UDK: 655.3.022:004.9

DOI: https://doi.org/10.24867/02EF04Ninkovic

\title{
ISPITIVANJE KVALITETA OTISAKA DOBIJENIH GRAFIČKIM SISTEMOM XEROX VERSANT 80
}

\section{EXAMINATION OF PRINT QUALITY OBTAINED XEROX VERSANT 80 GRAPHIC SYSTEM}

\section{Momčilo Ninković, Nemanja Kašiković, Rastko Milošević, Fakultet tehničkih nauka, Novi Sad \\ Oblast - GRAFIČKO INŽENJERSTVO I DIZAJN \\ 2. EKSPERIMENTALNI DEO}

Kratak sadržaj - Konstantnim porastom $i$ razvojem grafičke tehnologije, omogućeno je štampanje kvalitetnih otisaka. Da bi se dobijeni kvalitet konstantno održavao, potrebno je kontrolisati $i$ ispitivati kvalitet grafičkih proizvoda. U ovom radu ispitan je kvalitet otisaka koji je odštampan na četiri procesne boje (CMYK) i tri RGB boje dobijen tehnikom digitalne štampe.

Ključne reči: Digitalna štampa, ispitivanje kvaliteta, otisak

\begin{abstract}
By constant growth and development of graphic tehnology, we are enable to print quality obtained continuously, it is necessary to control and examine the quality of prints printed on four process colors $(C M Y K)$ and three $R G B$ colors obtained by the digital printing tehnique.
\end{abstract}

Keywords: Digital printing, print quality, proof

\section{UVOD}

Digitalna štampa je jedna od najmlađih tehnika štampanja koja je nastala 1991. godine. Za razliku od štamparskog postupka, pojam "digitalna štampa", podrazumeva štamparsku sliku koja do ulaska u štamparsku mašinu ostaje $\mathrm{u}$ digitalnoj formi i tek $\mathrm{u}$ mašini ponovo bude sastavljena $u$ analognu štamparsku sliku. Štamparski postupci se dele na dve vrste, gde se boja nanosi direktno na štamparsku formu i bez štamparske forme odnosno NIP (Non - Impact Printing) postupci koji se baziraju na digitalno-elektronskom upravljanju sistemom štampe. Najrasprostranjeniji NIP štamparski postupak je elektrofotografija, kod ovog procesa štampe pri svakom ciklusu štampanja štamparska slika se prenosi iznova na štamparsku formu, što znači da elektrofotografija ima dinamičku štamparsku formu [1].

Ponovljivost štampe je veoma bitna u svim vrstama štamparskih postupaka, pa tako i u digitalnoj štampi. Kod digitalne štampe ponovljivost štampe ne dovodi do značajne promenljivosti odštampanog uzorka, razlike $\mathrm{u}$ kvalitetu su veoma male, skoro neprimetne. Upravo zbog toga je postavljen cilj rada, a to je da se preko merenih vrednosti odredi kvalitet otisaka digitalne štamparske mašine.

\section{NAPOMENA:}

Ovaj rad proistekao je iz master rada čiji mentor je bio dr Nemanja Kašiković, vanr. prof.
Za potrebe eksperimenta, pripremljena je odgovarajuća test karta koje se odštampala na mašini Xerox Versant 80 (slika 1.) koji radi na principu elektrofotografije. Xerox Versant 80 Press obezbeđuje efikasni i brz prenos energije i koegzistentno fiksira otisak brzinom štampe od 80 otisaka u boji po minuti, takođe nudi najviši mogući kvalitet, bez ograničenja u vrstama medija i papira na kojima može da radi. Uređaj uzima u obzir težinu papira, količinu tonera i način štampe, te na osnovu tih parametara ispravlja papir i omogućava izradu ujednačenih i nedeformisanih otisaka. Ovako odštampani tabaci značajno olakšavaju poslove dorade [1].

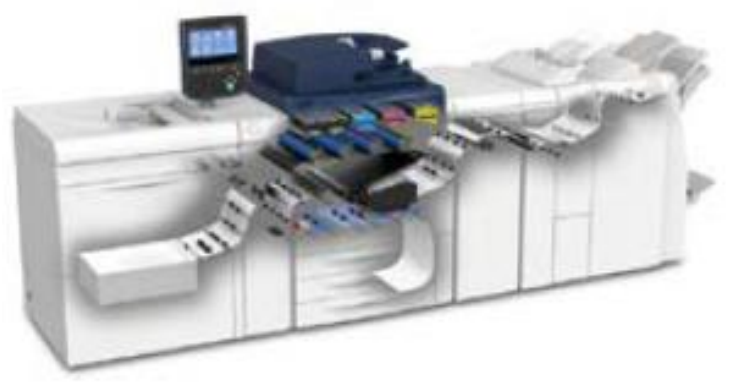

Slika 2. Xerox Versant 80

Kompanija Xerox je napravila četiri boje koje idu uz ovu mašinu za štampanje kako bi mogli snabdevati njihove korisnike [3].

Kao podloge za štampu korišćene su četiri vrste papira, koje su se razlikovale prema površinskoj masi i tipu premaza. Tako se test karta štampala na nepremaznim papirima od $80 \mathrm{~g} / \mathrm{m}^{2}$ (uzorak 1) i $120 \mathrm{~g} / \mathrm{m}^{2}$ (uzorak 2), kao i na premaznim papirima od $150 \mathrm{~g} / \mathrm{m}^{2}$ (uzorak 3) i 300 $\mathrm{g} / \mathrm{m}^{2}$ (uzorak 4).

U cilju određivanja optičkih osobina papira merene su belina, odnosno žutoća uzoraka papira koji zavise od načina izrade papira, kao i prisustvo različitih izbeljivača. Merenje beline $\mathrm{i}$ žutoće, kao i određivanje L*a*b vrednosti vršeno je uz pomoć uređaja SpektroDens Premium (merna geometrija $0 / 45^{\circ}$; standardni posmatrač $2^{\circ}$; standardno osvetljenje D50; tolerancija greške 0,3) [4].

Na svim pomenutim vrstama papira štampana je ista test karta na formatu A4 (210 x $297 \mathrm{~mm})$. Za potrebe eksperimentalnog dela generisana su polja cijana, magente, žute i crne, a takođe su generisana polja crvene, plave i zelene i na njima su izvršena merenja CIE L*a*b vrednosti. 


\section{REZULTATI ISTRAŽIVANJA}

Nakon izvršenog štampanja uzoraka pristupilo se procesu merenja vrednosti. Od svih izmerenih vrednosti, u nastavku su predstavljena merenja za optičku gustinu, CIE Lab i vrednosti za razliku boje.

\subsection{Optička gustina}

Na slici 2. prikazani su rezultati optičke gustine cijan boje.

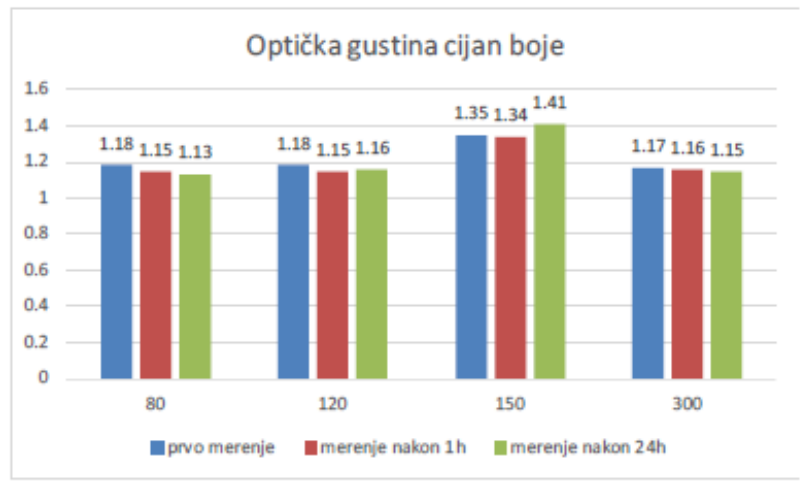

Slika 2. Grafički prikaz optičke gustine za cijan boju

Merenja pokazuju da je kvalitet odštampanih test karti cijan bojom $u$ različitim vremenskim intervalima približno isti, tj. nema značajnog odstupanja. Uočavaju se i različite vrednosti između papira što se može opravdati različitom površinskom masom i tipom premaza.

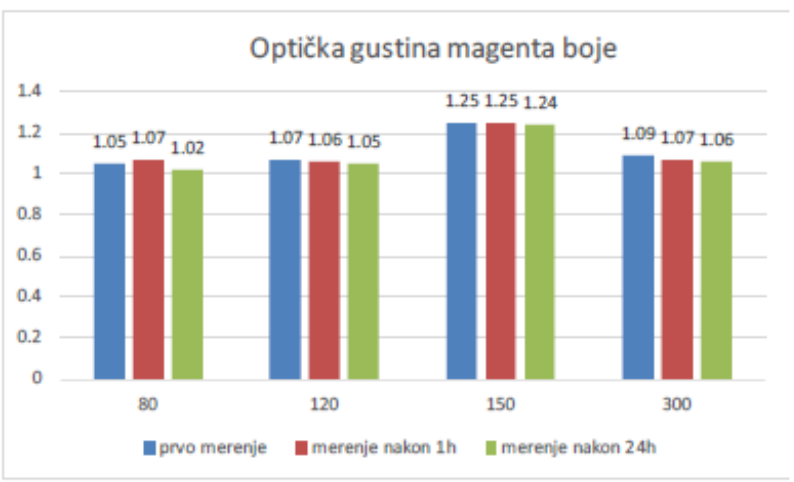

Slika 3. Grafički prikaz optičke gustine za magenta boju

Isti odnos se zapaža kod polja odštampanih magenta bojom. Optičke gustine tokom celokupnog procesa štampe su ujednačene, a kao i u prethodnom slučaju, uočava se da su najveće vrednosti izmerene kod uzorka broj 3.

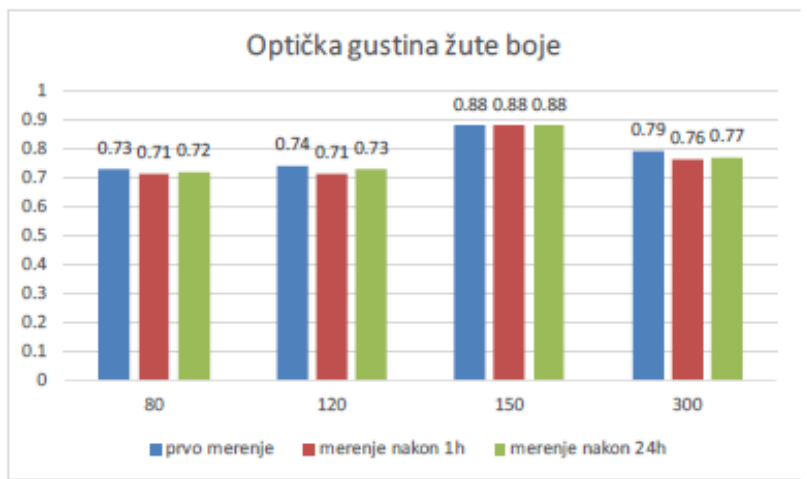

Slika 4. Grafički prikaz optičke gustine za žutu boju
Prema merenjima optičke gustine žute boje (slika 4), uočava se da je kvalitet otiska tog 24 časovnog procesa dobar i da nema značajnog odstupanja.

I ovde se uočavaju značajne razlike u vrednostima između odštampanih uzoraka, ako se gleda vrsta papira. Opet je uzorak 3 , tj premazni papir od $150 \mathrm{~g} / \mathrm{m}^{2}$, značajno odskočio.

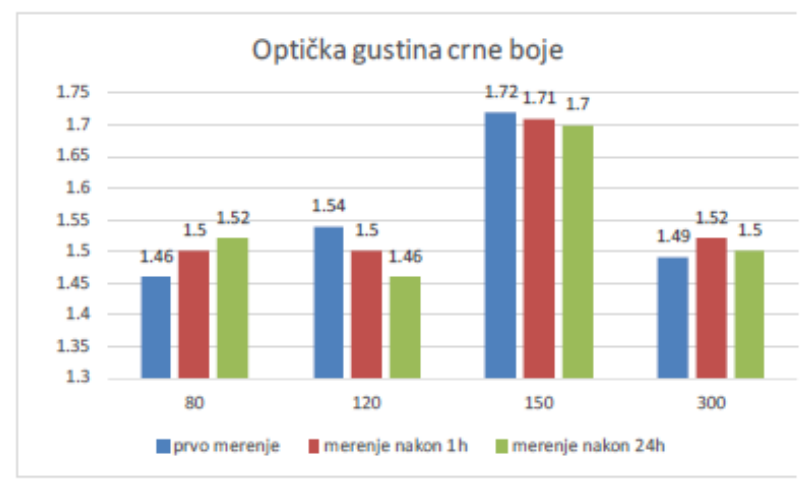

Slika 5. Grafički prikaz optičke gustine za crnu boju

Ukoliko se posmatraju polja na uzorcima odštampanim crnom (slika 5), crvenom (slika 6) i zelenom bojom (slika 7), može se primetiti isti trend kao i u prethodno analiziranim uzorcima.

Naime, optička gustina duž celokupnog procesa za sve uzorke je ujednačena, pri čemu se jedina odstupanja javljaju ukoliko poredimo pojedinačno papire.

Kao i u svim prethodno zabeleženim merenjima, uzorak 3 je značajno odskočio sa vrednostima optičke gustine.

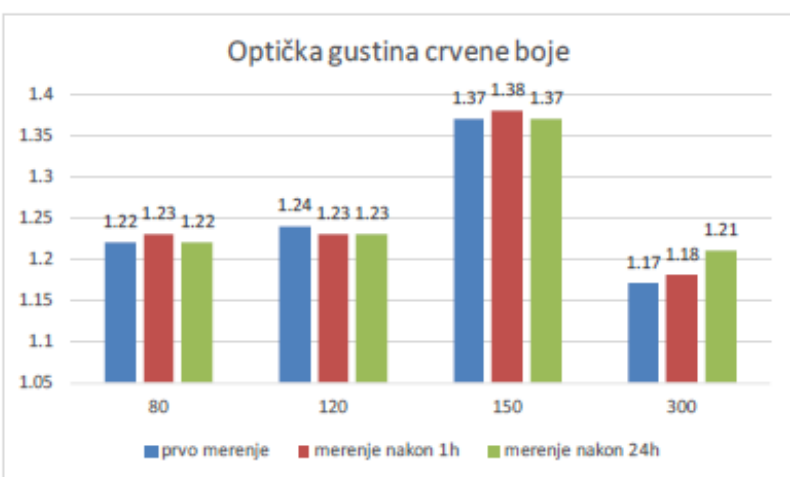

Slika 6. Grafički prikaz optičke gustine za crvenu boju

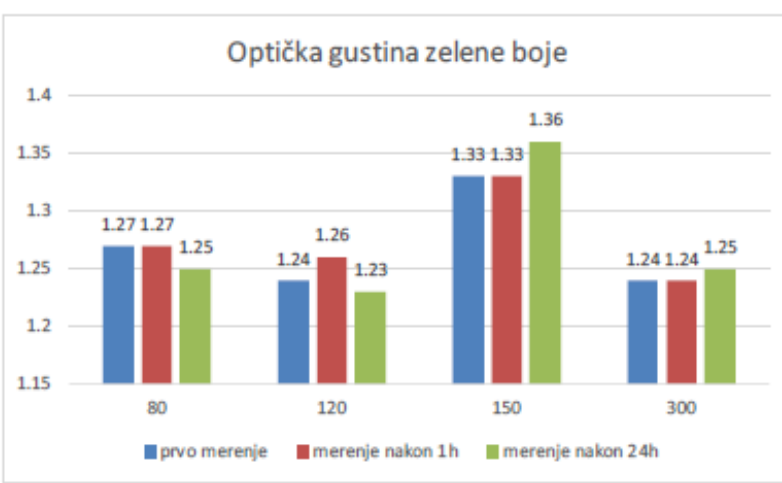

Slika 7. Grafički prikaz optičke gustine za zelenu boju 


\subsection{CIE $L * a * b$ vrednosti}

Izmerene vrednosti razlike boja $\Delta \mathrm{E}$ između standardizovanih i izmerenih vrednosti dobijene su pomoću metode CIEDE2000 i predstavljene su na slikama 8 - 11. Na slici 8. predstavljene su izmerene vrednosti razlike boje $\Delta \mathrm{E}$ kod $80 \mathrm{~g} / \mathrm{m}^{2}$ papira. Najveća odstupanja se javljaju RGB boja, a najmanja su kod cijan boje. Isti trend je zabeležen i kod $120 \mathrm{~g} / \mathrm{m}^{2}$ papira, tj najveća odstupanja su kod RGB boja, a kod CMYK boja i dalje najviše odstupa žuta, a najmanje crna boja. Kod uzorka 3, uočava se da su najveće vrednosti za razliku boje u odnosu na standard zabeleženi kod zelene i crvene boje. Kod procesnih boja, vrednosti su manje, ali ovaj put se uočava da je najmanja razlika u odnosu na standard zabeležena kod test polja odštampanih magenta bojom, a najveća kod test polja odštampanih crnom bojom.

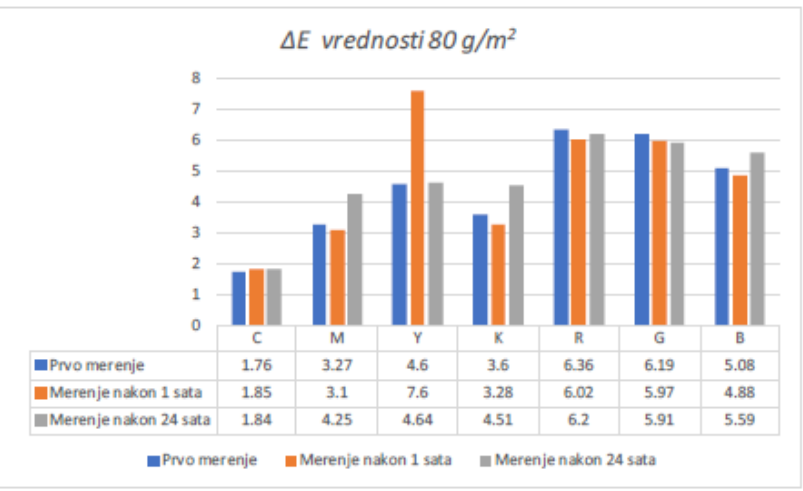

Slika 8. Grafički prikaz izmerene vrednosti razlike boje $\Delta E$ u odnosu na standard $\left(80 \mathrm{~g} / \mathrm{m}^{2}\right.$ papir $)$

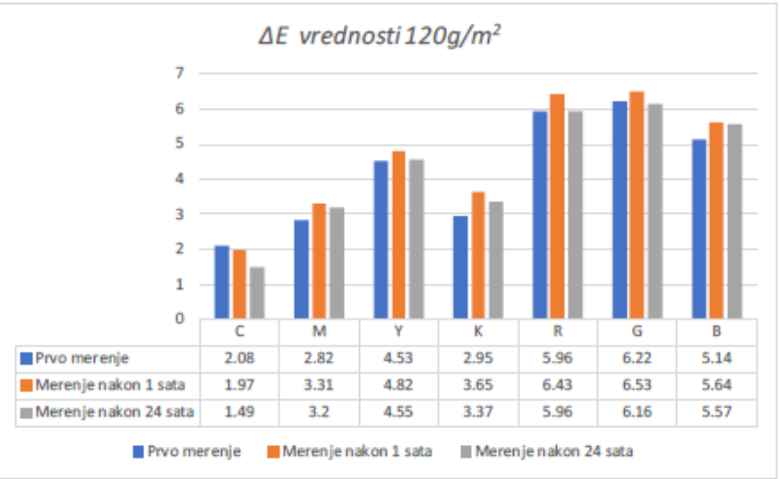

Slika 9. Grafički prikaz izmerene vrednosti razlike boje $\Delta E$ u odnosu na standard $\left(120 \mathrm{~g} / \mathrm{m}^{2}\right.$ papir $)$

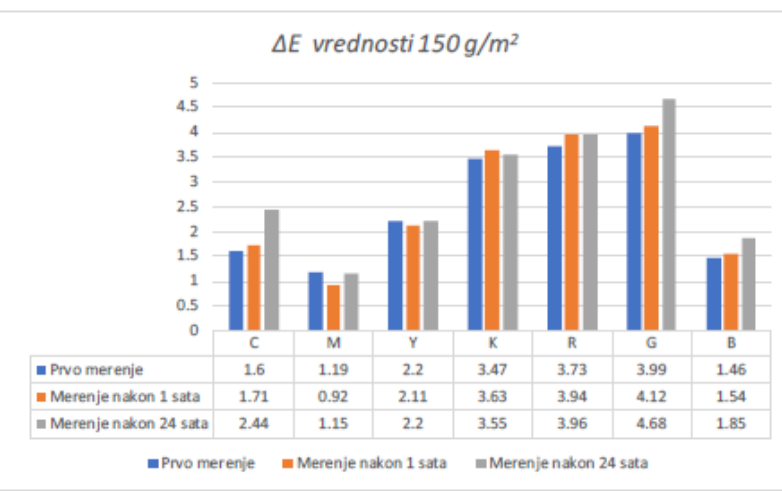

Slika 10. Grafički prikaz izmerene vrednosti razlike boje $\Delta E$ u odnosu na standard $\left(150 \mathrm{~g} / \mathrm{m}^{2}\right.$ papir $)$
$\mathrm{Na}$ slici 11. predstavljene su izmerene vrednosti razlike boje $\Delta \mathrm{E} \mathrm{u}$ odnosu na standard kada se kao podloga koristio $300 \mathrm{~g} / \mathrm{m}^{2}$ papir. Opet se uočavaju veća odstupanja kod test polja odštampanih RGB bojama, a najmanje vrednosti su izmerene kada su se polja odštampana cijan bojom poredila sa standardima.

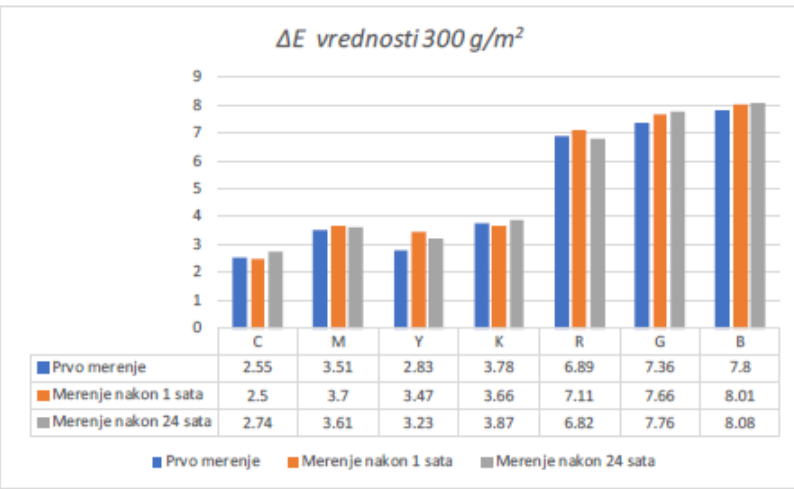

Slika 11. Grafički prikaz izmerene vrednosti razlike boje $\Delta E$ kod $300 \mathrm{~g} / \mathrm{m}^{2}$ papira

Mnogo precizniji rezultati se dobiju, ukoliko se odštampani uzorci porede međusobno i to je ono što je suštinski najbitnije, a to je da u procesu štampe imamo ujednačen kvalitet.

Tako su u tabelama 1-4 prikazane razlike boje između uzoraka odštampanih $\mathrm{u}$ različitim vremenskim intervalima.

Tabela 1. Međusobno poređenje odštampanih tabaka (80 $\mathrm{g} / \mathrm{m}^{2}$ papir)

\begin{tabular}{|l|l|l|l|l|l|l|l|}
\hline Uz. 1 & $\Delta E(C)$ & $\Delta E(M)$ & $\Delta E(Y)$ & $\Delta E(K)$ & $\Delta E(R)$ & $\Delta E(G)$ & $\Delta E(B)$ \\
\hline $\begin{array}{l}0-1 \\
\mathrm{~h}\end{array}$ & 1.17 & 1.29 & 6.43 & 0.46 & 1.46 & 0.75 & 1.14 \\
\hline $\begin{array}{l}0-24 \\
\mathrm{~h}\end{array}$ & 1.49 & 1.41 & 0.57 & 1.02 & 1.8 & 1.37 & 1.78 \\
\hline $\begin{array}{l}1-24 \\
\mathrm{~h}\end{array}$ & 2.58 & 1.62 & 6.15 & 1.49 & 0.62 & 0.75 & 1.48 \\
\hline
\end{tabular}

U tabeli 1. vidi se da najveće razlike boje postoje između otisaka odštampanih cijan pojom nakon 1 i 24 sata kod cijana, magente, žute i crne, dok kod crvene, zelene i plave međusobno poređenje ima najveće vrednosti kod prvog merenja i merenja nakon 24 sata.

Tabela 2. Međusobno poređenje odštampanih tabaka (120 $\mathrm{g} / \mathrm{m}^{2}$ papir)

\begin{tabular}{|l|l|l|l|l|l|l|l|}
\hline Uz. 1 & $\Delta E(C)$ & $\Delta E(M)$ & $\Delta E(Y)$ & $\Delta E(K)$ & $\Delta E(R)$ & $\Delta E(G)$ & $\Delta E(B)$ \\
\hline $\begin{array}{l}0-1 \\
\mathrm{~h}\end{array}$ & 1.63 & 0.7 & 1.58 & 0.96 & 0.99 & 0.98 & 0.93 \\
\hline $\begin{array}{l}0-24 \\
\mathrm{~h}\end{array}$ & 2.63 & 0.58 & 0.37 & 0.75 & 0.29 & 0.24 & 0.98 \\
\hline $\begin{array}{l}1-24 \\
\mathrm{~h}\end{array}$ & 1.31 & 1.02 & 1.78 & 0.38 & 1.03 & 0.92 & 0.52 \\
\hline
\end{tabular}

U tabeli 2. može se utvrditi da je najveće vrednosti za razliku boje ima međusobno poređenje kod cijana i plave nakon prvog merenje i merenje nakon 24 sata, kod magente, žute, crvene ima merenje nakon 1 i 24 sata, dok kod crne i zelene ima prvo merenje i merenje nakon 1 sata. 
Tabela 3. Međusobno poređenje odštampanih tabaka (150 $\mathrm{g} / \mathrm{m}^{2}$ papir)

\begin{tabular}{|l|l|l|l|l|l|l|l|}
\hline Uz. 1 & $\Delta E(C)$ & $\Delta E(M)$ & $\Delta E(Y)$ & $\Delta E(K)$ & $\Delta E(R)$ & $\Delta E(G)$ & $\Delta E(B)$ \\
\hline $\begin{array}{l}0-1 \\
\mathrm{~h}\end{array}$ & 0.19 & 1.39 & 0.78 & 0.19 & 0.47 & 0.95 & 1.05 \\
\hline $\begin{array}{l}0-24 \\
\mathrm{~h}\end{array}$ & 1.4 & 1.16 & 1.10 & 0.44 & 0.69 & 1.22 & 1.91 \\
\hline $\begin{array}{l}1-24 \\
\mathrm{~h}\end{array}$ & 1.43 & 0.71 & 0.87 & 0.43 & 0.59 & 1.81 & 1.04 \\
\hline
\end{tabular}

U tabeli 3. vidi se da je najveće međusobno poređenje za razliku boja kod cijana i zelene ima merenje nakon 1 i 24 sata, kod magente ima prvo merenje i merenje nakon 1 sata, a kod žute, crne, crvene i plave ima prvo merenje i merenje nakon 24 sata.

Tabela 4. Međusobno poređenje odštampanih tabaka (300 $\mathrm{g} / \mathrm{m}^{2}$ papir)

\begin{tabular}{|l|l|l|l|l|l|l|l|}
\hline Uz. 1 & $\Delta E(C)$ & $\Delta E(M)$ & $\Delta E(Y)$ & $\Delta E(K)$ & $\Delta E(R)$ & $\Delta E(G)$ & $\Delta E(B)$ \\
\hline $\begin{array}{l}0-1 \\
\mathrm{~h}\end{array}$ & 0.08 & 0.87 & 2.65 & 0.15 & 0.49 & 0.63 & 0.41 \\
\hline $\begin{array}{l}0-24 \\
\mathrm{~h}\end{array}$ & 1.18 & 0.65 & 1.88 & 0.27 & 0.54 & 1.11 & 0.97 \\
\hline $\begin{array}{l}1-24 \\
\mathrm{~h}\end{array}$ & 1.2 & 0.57 & 0.99 & 0.39 & 0.8 & 0.7 & 0.65 \\
\hline
\end{tabular}

U tabeli 4. može se utvrditi da se najveće razlike boje beleže nakon poređenje kod cijana, crne i crvene merenje nakon 1 i 24 sata, kod magente i žute ima prvo merenje i merenje nakon 1 sata, a kod zelene i plave ima prvo merenje i merenje nakon 24 sata.

\section{ZAKLJUČAK}

Osobine papira su veoma bitne kod štampe kao i kontrola kvaliteta štampe, jer se mora podesiti mašina prema osobinama papira kao što su premazni, nepremazni, gramatura papira, format. Prilikom štampanja uzoraka koji su se koristili za ovaj zadatak vršeno je prethodno podešavanje mašine (prvo se podesilo na mašini o specifikacijama papira, a zatim na računaru koji je povezan sa štamparskom mašinom odakle je učitan fajl koji se štampao). Nakon štampe je vršeno merenje radi ispitivanja kontrole kvaliteta odštampanog uzorka.
Kontrolom kvaliteta odštampanog uzorka dolazi se do zaključka da uzorci koji su odštampani u različitim vremenskim intervalima ne gube na kvalitetu i postojanosti otiska. Razlika između otiska koji su štampani $u$ različitim vremenskim intervalima $i$ na različitim vrstama papira je minimalna, odnosno međusobna odstupanja nisu velika.

\section{LITERATURA}

[1] Kašiković, N., (2013) Materijal sa predavanja Tehnike štampe.

[2] Alfadigital.rs (2015) [Online] Dostupno na: http:/www.alfadigital.rs/Novosti/izdvojite-se-od-ostalihjednostavno-najbolje:-xerox-versant-80-digital-press.

[3] Xerox.com (2018) [Online] Dostupno na: https://www.xerox.com/digital-printing/digital-printing -press/color-printing/xerox-versant-80/enus.html.

[4] Colormanagement.com (2018) [Online] Dostupno na:

https://www.colormanagement.com/store/CID25/PID8 92.

[5] Canon (2018) [Online] Dostupno na: https://www.canon.rs/scanners/flatbedscanners/canoscan_5600f/

\section{Adresa za kontakt:}

MsC Momčilo Ninković, ninkovicmomcilo@yahoo.com

Dr Nemanja Kašiković, knemanja@uns.ac.rs

MsC Rastko Milošević, rastko.m@uns.ac.rs 